УДК 159.953.5

\title{
КОГНИТИВНЫЙ СТИЛЬ КАК КРИТЕРИЙ УСПЕШНОСТИ В ШАХМАТНОЙ ИГРЕ МЛАДШИХ ШКОЛЬНИКОВ-ШАХМАТИСТОВ
}

\author{
Алёхина Анна Владимировна \\ аспирант факультета психологии \\ Таврической академии ФГАОУ ВО КФУ \\ им. В.И. Вернадского, г. Симферополь
}

Аннотация: В статье рассматриваются различные критерии успешности младших школьников-шахматистов, регулярно и мотивировано посещающих шахматные кружки. Рассматривается понятие успешности ребёнка в обучении в целом, приводится анализ мнения опытных шахматных детских тренеров и выдающихся шахматистов относительно понятия «успешность в шахматной игре».

В статье в целом рассматривается понятие «успешность» как психологгическая характеристика.

В первой части статьи рассматриваются психологические факторы, помогающие или мешающие ребёнку младшего школьного возраста считать себя и считаться успешным шахматистом. В проведенном исследовании с помощью методики определения когнитивного стиля импульсивностьрефлективность Кагана и авторской методики шахматного тренера Колокольцева В.Г., в зависимости от соотношения скорости и точности принятия решения были определены и описаны четыре типа детей, соответствующие различным полюсам когнитивного стиля импульсивностьрефлективность (импульсивный-точный, импульчивный-неточный, рефлективный-точный, рефлективный-неточный). Основное различие между полюсами импульсивности и рефлективности заключается в объеме той информации, которую собирает индивидуум до принятия решения: импульсивные лица принимают решения на недостаточной информационной основе, тогда как рефлективные лица склонны принимать решения на максимально полной информации о ситуации.

После приведения результатов исследования детей-шахматистов младших школьников разного возраста, были предложены психологические методы преобразования различных типов рефлективности-импульсивности в 
наиболее оптимальный для успешности в шахматной игре, а именно импульсивный-точный.

Ключевые слова: Успешность в шахматной игре, шахматная игра, младший школьник, импульсивный, рефлективный, критерии успешности.

\title{
COGNITIVE STYLE AS A CRITERION OF SUCCESS IN THE CHESS GAME OF JUNIOR SCHOOL CHESS PLAYERS
}

Aliohina A.V.

\begin{abstract}
The article discusses various criteria for the success of junior schoolchildren-chess players who regularly and motivated attending chess clubs. The concept of a child's success in learning as a whole is considered, an analysis of the opinion of experienced chess children coaches from different cities regarding the concept of "success in a chess game" is given.

The article as a whole considers the concept of "success" as a psychological characteristic.

The first part of the article examines the psychological factors that help or prevent a child of primary school age from considering himself and being considered a successful chess player. In this study, using the methodology for determining the cognitive style of Kagan's impulsivity-reflexivity and the author's methodology of the chess coach Kolokoltsev V. G., depending on the ratio of the speed and accuracy of decision-making, four types of children were identified and described, corresponding to different poles of the cognitive style, impulsivity-reflexivity (impulsive-precise, impulsive-imprecise, reflective- accurate, reflective-imprecise).

The main difference between the poles of impulsivity and reflectivity lies in the amount of information that an individual collects before making a decision: impulsive individuals make decisions on an insufficient information basis, while reflective individuals tend to make decisions based on the most complete information about the situation.
\end{abstract}

Key words: Psychological training, chess game, preschool child, junior school student, impulsive, reflective, success criteria.

Введение. Вызывает интерес проблема определения понятия «успешность» в шахматной игре младших школьников. Вообще, можно ли говорить о повышении уровня успешности начинающих шахматистов? 
Диференциация начинающих шахматистов по типам когнитивного стиля импульсивность-рефлективность, а именно, импульсивный точный, импульсивный неточный, рефлективный точный, рефлективный неточный помогает раскрыть понятие «успешности» и преобразовать мешающие этому факторы.

\section{Постановка проблемы.}

Юные шахматисты-младшие школьники в силу своего возраста, а также особенностей когнитивного стиля часто бывают неусидчивыми и импульсивными в принятии решений во время шахматной партии. Высокая концентрация внимания, нарабатываемый опыт и знания различных шахматных комбинаций и стандартных положений помогают делать эти решения точными, выигрышными, а значит успешными.

Цель статьи: описать исследование, позволившее определить критерии вероятной успешности в шахматной игре младших школьников - начинающих шахматистов.

\section{Изложение основного материала.}

Исследование предварял вопрос: можно ли в принципе считать начинающих шахматистов успешными, если у них только формируются навыки игры и мотивация к игре, а также продолжается развитие основных и необходимых для шахматной игры навыков трудолюбия, концентрации внимания, умения действовать в уме, становление умений выстраивать отношения с окружающими людьми в различных социальных группах, грамотно реагировать на различные стрессовые ситуации, в том числе проигрыш в партии.

Анализ психолого-педагогической литературы и беседы с экспертами, которыми мы считали тренеров по шахматам, позволяет предложить трактовку понятия успешность.

Успешность - это качество личности, позволяющее достигать позитивно высоких результатов в овладении социальными ролями, в различных видах деятельности имеющих общественное признание, в общении. Успешность можно рассматривать как результат благоприятного формирования личности ребенка, удовлетворения потребностей, в развитии задатков и реализации способностей.

Успешность в шахматной игре - является интегральной шахматной способностью, включающей в себя несколько составляющих: операциональные особенности интеллекта (память, скорость мышления, скорость принятия 
решения, точность в принятии решений, эмоционально-волевые составляющие (эмоциональная устойчивость, стрессоустойчивость, умение противостоять давлению противника, оптимальный тип нервной системы, позволяющий достаточно быстро и точно принимать решения), личностные составляющие (мотивация, общий интеллект ребёнка, объем знаний, позволяющий видеть несколько вариантов решения и выбирать наиболее правильный, интуиция).

Симферопольский тренер Колокольцев В. Г. полагает, что успешность в шахматной партии заключается в умении правильно оценивать позицию и использовать стратегические и тактические приёмы для выигрыша партии. Для успешной шахматной игры юному шахматисту необходимо иметь высокую концентрацию внимания, умение абстрагироваться, логическое и системное мышление. Люди неуверенные, с проблемами в концентрации и распеределении внимания не смогут быть успешными в шахматной игре. Ткаже нужно обладать нестандартным мышлением - видеть альтернативные подходы к решению задачи. Такое мышление складывается из креативности и интуиции. Так или иначе просчитать ходы могут все, но побеждает тот, у кого ярче выражены фантазия и воображение. Очень важно для успешности в шахматной игре иметь физическю подготовку, необходимое физическое развитие, что помогает шахматисту быть выносливым, иметь высокую стрессоустойчивость и «иммунитет» к поражениям.

Тренер шахматной школы им. С.Карякина в г. Симферополе Курбединов Рамис Ясерович считает, что очень сложно определить критерии успешности в шахматной игре в детском возрасте, т.к. дети настроены в основном на игру, на соревнование и редко проявляют какие-либо особенности. В младшем школьном возрасте шахматная игра направлена на развитие когнитивных функций (трудолюбие, усидчивость, умение действовать в уме). Критерием успешности для них может стать хорошая механическа, зрительная, образная пам'ять. Опираясь на эти особенности они могут запомнить последовательности и комбинации, применяя их в игре. Именно феноменальная память помогла М.Талю стать чемпионом мира. Он в детстве запоминал сложнейшие медицинские лекции отца, на которых присутствовал, а однажды воспроизвел одну из них студентам слово в слово.

Зам. директора шахматной школы им. Карякина г. Симферополь, тренер Губатенко Наталья Юрьевна: успешность в шахматной игре младшего школьника можно определить как возможность ребёнка применить теорию на практике. Критериями успешности могут быть: хорошая память, хорошая 
физическая подготовка (здоровые, физически активные дети имеют определённый уровень выносливости, необходимый для участия в соревнованиях), умение ребёнка психологически себя настроить (многие дети хорошо играющие на уроке, начинают бояться соперника на соревновании только узнав, что он по рангу выше и становятся неспособными показать все свои отработанные игровые навыки. Преодолевая этот страх или не зная с кем играют, они могут быть успешными в турнире, одерживая победу даже над более сильным шахматным соперником.

Тренер шахматной школы им. С.Карякина в г. Симферополе Жук Владимир Витальевич: успешность в шахматной игре - это способность выигрывать шахматные партии. Важным критерием успешности в шахматной игре младшего школьника является психологическая устойчивость, а именно способность не отвлекаться во время игры на окружающую обстановку, уметь спокойно отражать психологические атаки и манипуляции соперника, если таковые возникают. Добавим от себя, что это близко к таким характеристикам когнитивного стиля как полезависимость-поленезависимость.

Чемпион мира по шахматам Х.Р.Капабланка считал, что успешность юных шахматистов - это умение сосредоточиться на группе прорывных фигур, создавая на доске три уровня значимости фигур и распределяя подконтрольные поля доски на два уровня: значимые и не значимые [4].

А. Нимцович в своей книге «Моя система» пишет о том, что нужно для успешности в шахматной игре: «у каждого игрока свой собстственный почерк в постановке целей и решении проблем. Чёткая стратегия при этом не исключает гибкости стратегического мышления. Секрет разработки успешной стратегии осознание своих достоинств и недостатков и умение использовать свои сильные стороны» [7 ].

Успешным стилем М. Ботвинника являлась строгая самодисциплина, упорный труд, научный подход. Для М. Таля - это воля бурной творческой фантазии. Т. Петросян владел искусством защиты, выстраивал идеальную оборону, сковывая силы своих противников, использовал чужие ошибки. Он применял стратегию «бдительного бездействия» - искал угрозы со стороны соперника, устраняя их в зародыше, а когда сам становился неуязвимым начинал создавать свои угрозы. Это был его «уникальный стиль». Каждому шахматисту нужно иметь чёткое представление о своём стиле со всеми его достоинствами и недостатками. Нельзя стать чемпионом, не обладая способностью изменять свой стиль игры, когда это необходимо, адаптироваться 
к меняющимся обстоятельствам. Обдумывать перемены нужно тщательно, а осуществлять - решительно. Побеждает тот, кто оказывается хладнокровнее, расчётливее, увереннее в себе [5 ].

Гипотеза. Наиболее успешным шахматистом по шкале импульсивности рефлективности считаем ребёнка с импульсивным-точным когнитивным стилем. Критериями успешности такого шахматного игрока будет скорость принятия решения, а также при наличии высокой концентрации внимания, интуиции и знания различных комбинаций - точность принятия решения, конструктивно развивающего шахматную партию и приводящего впоследствии к выигрышу.

Цель исследования: выявить степень когнитивной импульсивностирефлективности у младших школьников, регулярно занимающихся шахматами.

Предмет исследования: латентное время первого ответа, количество ошибок (методика Дж. Кагана); скорость и точность нахождения правильного хода для того, чтобы поставить мат в один ход (методика В. Г. Колокольцева).

\section{Методики исследования:}

1. Основываясь на подходе М. Холодной к когнитивным стилям как квадриполярным измерениям (феномен «расщепления» полюсов стиля) для определения степени когнитивной импульсивности/рефлективности применена методика «Сравнение похожих рисунков» (Kagan, 1966). Были использованы две переменные: латентное время первого ответа и количество ошибок испытуемого. Испытуемому предъявляется 2 тренировочных, затем 12 основных листов, на каждом из которых сверху находится изображение знакомого предмета (фигура-эталон), а внизу располагаются в два ряда 8 почти идентичных изображений этого же предмета, среди которых только одно полностью идентично фигуре-эталону. Испытуемый должен найти и указать изображение, полностью идентичное фигуре-эталону.

Данный когнитивный стиль, в соответствии с первоначальным предположением Дж. Кагана, характеризует индивидуальные различия в склонности принимать решения быстро, либо медленно. Наиболее ярко это стилевое свойство проявляет себя в условиях неопределенности, когда требуется осуществить правильный выбор из некоторого множества альтернатив. Импульсивные испытуемые склонны быстро реагировать в ситуации множественного выбора, при этом гипотезы выдвигаются без анализа всех возможных альтернатив. Для рефлективных испытуемых характерен замедленный темп реагирования в подобной ситуации, гипотезы проверяются и 
многократно уточняются, решение принимается на основе тщательного предварительного анализа признаков альтернативных объектов.

В качестве показателя импульсивности-рефлективности используются показатели суммарного по 12 заданиям латентного времени первого ответа и суммарного количества ошибок. Чем выше латентное время первого ответа и меньше количество ошибок, тем в большей степени испытуемый характеризуется рефлективным стилем, и наоборот, импульсивный стиль характеризуется низким значением латентного времени и большим количеством ошибок.

2. Авторская методика шахматного тренера г. Симферополя В.Г. Колокольцева. Согласно данной методике, ребёнок должен решить четыре шахматные задачи на постановку мата в один ход. Задачи двух уровней сложности, в каждой из них есть шахматная ловушка - ход, который на первый взгляд может показаться матом, но впоследствии оказывается просто угрозой королю (шах). Есть единственно правильный ход, который нужно разглядеть и обозначить быстро и точно, что будет подтверждать результаты, полученные с помощью методики Кагана.

\section{Общая характеристика выборки:}

В исследовании приняли участие 30 младших школьников в возрасте от 7 до 11 лет, имеющие различный шахматный стаж. Все дети занимаются игрой в шахматы регулярно и под руководством тренеров. Представители выборки различаются по трём факторам: пол, возраст и шахматный стаж: начинающие шахматисты (от месяца до трёх), опытные шахматисты - дети, регулярно играющие в шахматы от года до 3-х лет.

\section{Ход исследования:}

Процесс работы по методике Кагана, позволяет обратить внимание и выявить следующие виды когнитивного стиля импульсивный-рефлективый быстрый (импульсивный) точный, быстрый (импульсивный) неточный, медленный (рефлективный) точный, медленный (рефлективный) неточный. В итоге выяснилось, что каждому ребенку в большей мере соответствует один из стилей и в меньшей - другие стили.

Во всех исследованиях, где применялась эта методика, сообщается об отрицательной корреляции между показателями времени первого ответа и количеством временем ошибок. Исследуется влияние проявления эмоционально - волевого компонента успешности младших школьников в шахматной игре, а именно, насколько тип нервной системы, скорость, быстрота 
и точность в принятии решений во время шахматной партии помогает ребёнку быть успешным в шахматах. Насколько ребёнок сам себя считает успешным, насколько родители считают его успешным, насколько тренер считает его успешным, насколько его партнёры по игре считают его успешным.

Таблица 1

\section{Результаты теста Кагана}

\begin{tabular}{|c|c|c|c|c|c|}
\hline № & имя & возраст & $\begin{array}{c}\text { Шахматный } \\
\text { стаж }\end{array}$ & $\begin{array}{c}\text { Латентное } \\
\text { время первого } \\
\text { ответа (сек) }\end{array}$ & $\begin{array}{l}\text { Количество } \\
\text { ошибок (шт) }\end{array}$ \\
\hline 1 & Дима & 7 лет & $3 \mathrm{мес}$ & 124 & 26 \\
\hline 2 & Марк & 7 лет & 4 мес. & 101 & 12 \\
\hline 3 & Максим & 7 лет & $3 \mathrm{mec}$ & 189 & 13 \\
\hline 4 & Зоя & 11 лет & 6 лет & 161 & 3 \\
\hline 5 & Алекса & 8 лет & 2 мес & 187 & 11 \\
\hline 6 & Ира & 8 лет & $2 \mathrm{Mec}$ & 264 & 6 \\
\hline 7 & Асан & 9 лет & 2 года & 164 & 3 \\
\hline 8 & Серёжа & 7 лет & 3 года & 299 & 9 \\
\hline 9 & Святослав & 8 лет & 2 года & 234 & 5 \\
\hline 10 & Люба & 11 лет & 4 года & 368 & 4 \\
\hline 11 & Катя & 7 лет & 2 мес & 155 & 28 \\
\hline 12 & Костя & 7 лет & 4 мес & 523 & 5 \\
\hline 13 & Оля & 7 лет & $4 \mathrm{мес}$ & 217 & 8 \\
\hline 14 & Коля & 7 лет & $4 \mathrm{Mec}$ & 263 & 3 \\
\hline 15 & Маша & 7 лет & 2 мес & 58 & 6 \\
\hline 16 & Ибрагим & 7 лет & 5 мес & 189 & 5 \\
\hline 17 & Саша & 11 лет & 3 года & 723 & 4 \\
\hline 18 & Артём & 9 лет & 4 года & 234 & 5 \\
\hline 19 & Кирилл & 9 лет & 4 года & 237 & 4 \\
\hline 20 & Тимур & 11 лет & 2 года & 175 & 6 \\
\hline
\end{tabular}




\begin{tabular}{|c|l|c|c|c|c|}
\hline \hline 21 & Илья & 11 лет & 3 мес & 300 & 1 \\
\hline 22 & Матвей & 8 лет & 1 год & 156 & 6 \\
\hline 23 & Лев & 11 лет & 2 года & 443 & 4 \\
\hline 24 & Миша & 7 лет & 3 мес & 186 & 13 \\
\hline 25 & Мирослав & 9,5 лет & 1 мес & 442 & 11 \\
\hline 26 & Кирилл & 11 лет & 3 года & 330 & 1 \\
\hline 27 & Владимир & 11 лет & 4 мес & 318 & 1 \\
\hline 28 & Анна & 11 лет & 2 года & 102 & 1 \\
\hline 29 & Даша & 9 лет & 2 года & 287 & 4 \\
\hline 30 & Влад & 11 лет & 3 года & 250 & 3 \\
\hline
\end{tabular}

Таблица 2

Результаты теста Колокольцева

\begin{tabular}{|c|l|c|c|c|c|}
\hline № & имя & возраст & $\begin{array}{c}\text { Шахматный } \\
\text { стаж }\end{array}$ & $\begin{array}{c}\text { Время } \\
\text { первого } \\
\text { ответа }\end{array}$ & $\begin{array}{c}\text { Количество } \\
\text { ошибок }\end{array}$ \\
\hline 1. & Дима & 7 лет & 3 мес & 8 сек & 5 \\
\hline 2 & Марк & 7 лет & 4 мес & 49 сек & 6 \\
\hline 3 & Максим & 7 лет & 3 мес & 30 сек & 2 \\
\hline 4 & Зоя & 11 лет & 6 лет & 35 сек & 1 \\
\hline 5 & Алекса & 8 лет & 2 мес & 21 сек & 5 \\
\hline 6 & Ира & 9 лет & 2 мес & 41 сек & 4 \\
\hline 7 & Асан & 7 лет & 3 года & 24 сек & 1 \\
\hline 8 & Серёжа & 8 лет & 2 года & 64 сек & 3 \\
\hline 9 & Святослав & 11 лет & 4 года & 85 сек & 1 \\
\hline 10 & Люба & 7 лет & 2 мес & 82 сек & 3 \\
\hline 11 & Катя & 7 лет & 4 мес & 17 сек & 3 \\
\hline 12 & Костя & 7 лет & 4 мес & 28 сек & 4 \\
\hline 13 & Оля & & & 3 \\
\hline
\end{tabular}




\begin{tabular}{|c|l|c|c|c|c|}
\hline \hline 14 & Коля & 7 лет & 4 мес & 263 & 3 \\
\hline 15 & Маша & 7 лет & 2 мес & 11 сек & 3 \\
\hline 16 & Ибрагим & 7 лет & 5 мес & 15 сек & 4 \\
\hline 18 & Ааша & 11 лет & 3 года & 92 сек & 3 \\
\hline 19 & Кирилл & 9 лет & 4 года & 22 сек & 1 \\
\hline 20 & Тимур & 11 лет & 2 года & 30 сек & 2 \\
\hline 21 & Илья & 11 лет & 3 мес & 35 сек & 1 \\
\hline 22 & Матвей & 8 лет & 1 год & 17 сек & 3 \\
\hline 23 & Лев & 11 лет & 2 года & 52 сек & 2 \\
\hline 24 & Миша & 7 лет & 3 мес & 23 сек & 5 \\
\hline 25 & Мирослав & 9,5 лет & 1 мес & 46 сек & 4 \\
\hline 26 & Кирилл & 11 лет & 3 года & 37 сек & 1 \\
\hline 27 & Владимир & 11 лет & 4 мес & 28 сек & 0 \\
\hline 28 & Анна & 11 лет & 2 года & 17 сек & 0 \\
\hline 29 & Даша & 9 лет & 2 года & 24 сек & 2 \\
\hline 30 & Влад & 11 лет & 3 года & 19 сек & 1 \\
\hline
\end{tabular}




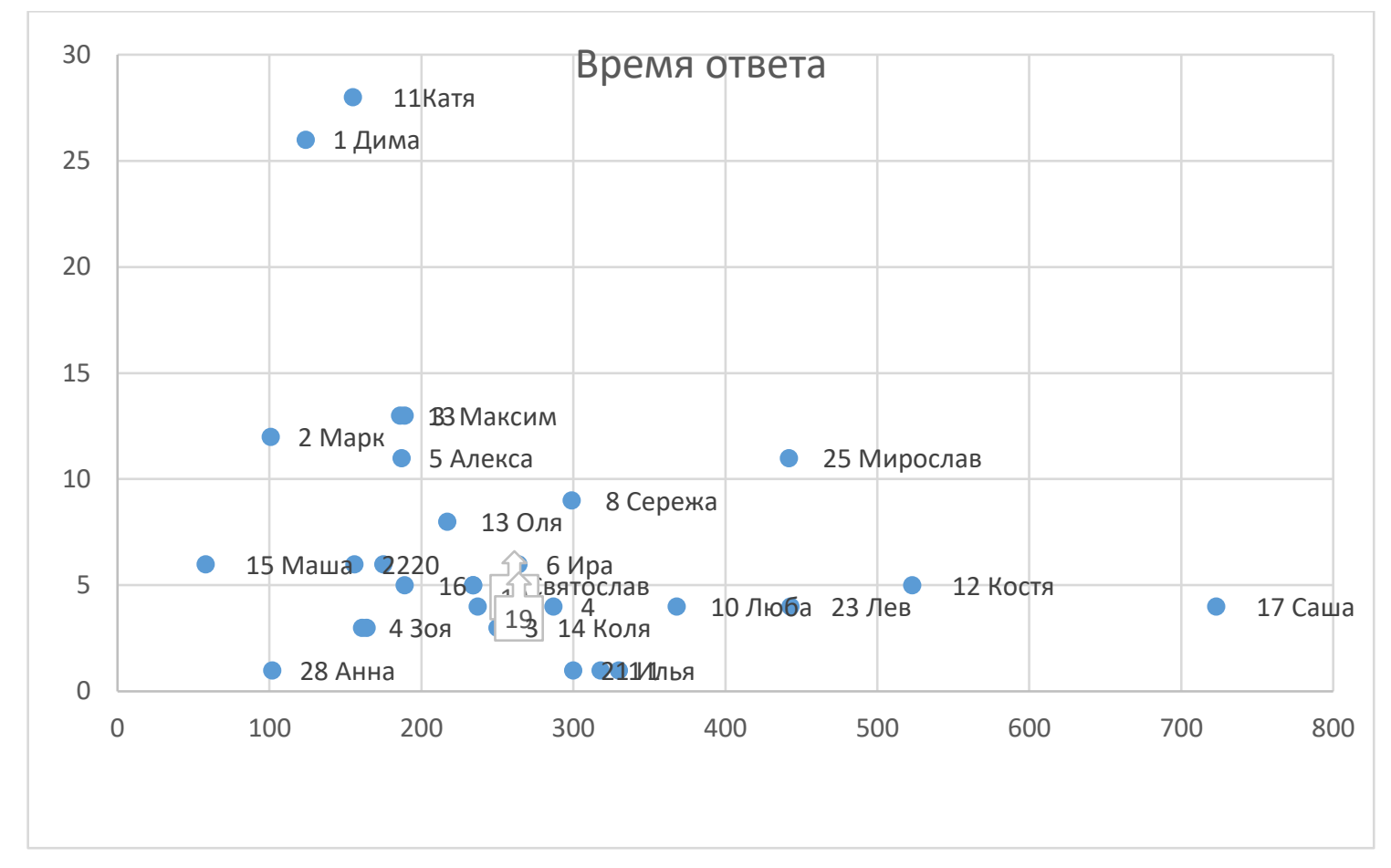

Чем правее на графике находится ребёнок, тем он более рефлективный, а значит тщательно и долго обдумывает свои решения, чем выше на графике ребёнок, тем он более неточный. Условно будем разделять график на 4 сектора импульсивный-точный, импульсивный- неточный, рефлективный - точный, рефлективный - неточный. Все результаты теста Кагана подкреплены результатами теста Колокольцева.

\section{Выводы}

1. На основе сопоставления результатов исследования, то есть принадлежности того или иного ребенка к тому или иному когнитивному стилю с объективным критерием - количеством выигранных партий за определенный период времени доказана гипотеза о когнитивном стиле как о сущностном критерии успешности младших школьников в шахматной игре. Наиболее успешными шахматистом являются дети с импульсивным-точным когнитивным стилем. Показателями преобладания этого когнитивного стиля являются: скорость принятия решения, точность принятия решения, конструктивно развивающего шахматную партию и приводящее впоследствии к выигрышу.

2. Ребёнок, для которого характерен импульсивный - точный стиль, обладает великолепной интуицией и большой практической базой, т.е. он делает первый ход и видит уже вперёд на несколько ходов, а когда соперник делает второй ход, он уже просчитывает следующие комбинации. Шахматное 
развитие такого ребенка предполагает уделить внимание формированию навыков рефлексивно-точного стиля.

3. Если ребенку присущ импульсивный-неточный стиль, то может развится страх ошибки, тем более, что практика дает для этого основание. Грамотная работа с такой формой страха позволяет трансформировать этот стиль в рефлексивный-точный и, как промежуточный вариант - в импульсивный-точный.

4. У детей с рефлективно-точным стилем очень развита сверхответственность или сверхосторожность - они по несколько раз проверяют правильность выбранного хода. Такому ребёнку нужно помочь избавится от страха ошибиться, что позволяет сформировать у юного шахматиста импульсивный-точный стиль.

5. Наиболее сложная ситуация с детьми, которым свойственен рефлективный-неточный стиль. Основная задача - сформировать мобильный когнитивный стиль, то есть, умение применять рефлективный- точный или импульсивный-точный.

\section{Список литературы}

1. Акишина В. В. «Как определить способности к обучению шахматной игре ребёнка 5-7 лет» / B. В. Акишина. Режим доступа: URL: https://nsportal.ru/shkola/vneklassnaya-rabota/library/2013/02/08/kak-opredelitsposobnosti-k-obucheniyu-shakhmatnoy

2. Алехин А.А. На пути к высшим шахмат. достижениям. М.: ФиС, 1991. URL: http://d4-d5.ru/wp-content/uploads/2013/08/Алехин-На-пути-к-высшимшахматным-достижениям-1991-г.pdf

3. Ботвинник М. М. Аналитические и критические работы 1942 - 1956 гг. - М.: ФиС, 1985.Москва, 2007. https://www.studmed.ru/botvinnik-mmanaliticheskie-i-kriticheskie-raboty-1923-1941_12a8079b564.html

4. Капабланка X.P. Учебник шахматной игры. Москва, 1983 file:///C:/Users/001/Downloads/2017-uchebnik_shakhmatnoy_igry_kapablanka.pdf

5. Каспаров «Шахматы как модель жизни» URL: http://d4-d5.ru/wpcontent/uploads/2013/09/Kasparov-SHahmaty-kak-model-zhizni.pdf

6. Крогиус Н. В. «Шахматы - школе»/ сост. Б. С. Гершунский, А. Н. Костьев; под ред. Б. С. Гершунского, Н. В. Крогиуса, В. С. Хелемендика. - М.: Педагогика, 1991. - 336 с. URL: https://klex.ru/mdy 
7. Нимцович А. Моя система. Москва, 1974. URL: http://padaread. com/?book $=25522$

8. Методическая разработка «Как мотивировать детей к игре в шахматы.» тренер-преподаватель Тесля И.Г. МБУ ДО ДЮСШ №4 г. Волгодонск, 2019г. URL: https://infourok.ru/motiviruem-detey-k-igre-v-shahmati3982788.html

9. Теория и практика шахматной игры. Под ред. Я. Б. Эстрина. - М.: Высшая школа, 1984. 